06

\title{
Работа выхода электрона углеродных нанокомпозитных пленок по данным вакуумной и атмосферной фотоэмиссии
}

\author{
(ㄱ Д.А. Бокизода, А.Ф. Зацепин, Е.А. Бунтов, А.И. Слесарев \\ Уральский федеральный университет имени первого Президента России Б.Н. Ельцина, \\ 620002 Екатеринбург, Россия \\ e-mail: bobot92@mail.ru
}

Поступило в Редакцию 21ноября 2019 г.

В окончательной редакции 21 ноября 2019 г.

Принято к публикации 19 декабря 2019 г.

\begin{abstract}
Методами фотостимулированной электронной эмиссии (Optically Stimulated Electron Emission - OSEE) и атмосферной фотоэмиссионной спектроскопии (Ambient pressure photoemission spectroscopy - APS) изучены энергетические характеристики карбиносодержащих пленок на медной и кремниевой подложках. Определены средняя контактная разность потенциалов и работа выхода, рассчитаны положения уровня Ферми для карбиносодержащих пленок различной толщины. Установлено, что работа выхода электронов и положение уровня Ферми исследованных образцов пленок не зависят от толщины пленки и типа подложки. Показана информативность методов OSEE и APS для оценки качества углеродных покрытий на подложках.
\end{abstract}

Ключевые слова: карбин, фотоэмиссия, энергетическая структура, работа выхода, атомная структура.

DOI: $10.21883 / J T F .2020 .06 .49287 .369-19$

Внимание исследователей к углеродным материалам объясняется их уникальными физико-химическими особенностями и перспективами практического применения в различных областях от медицины до наноэлектроники. Одним из типов структур, представляющих для наноэлектроники наибольший интерес, являются пленочные структуры. Такими пленками могут служить ориентированные пленки линейно-цепочечного углерода (ЛЦУ), состоящие из изогнутых углеродных цепей, ориентированных перпендикулярно поверхности подложки, и получаемые методом ионно-стимулированного осаждения. Наряду с пленками ЛЦУ для изучения представляет интерес и кристаллическая модификация ЛЦУ - кристалл карбина. Поскольку сшивки между цепочками, которые присутствуют в структуре кристалла, могут рассматриваться как каналы проводимости, то огромный интерес представляют исследования электронных свойств кристаллов. Для прогнозирования и расчета электрофизических свойств гетероструктур на основе ЛЦУ требуются данные по энергетическим характеристикам поверхностных слоев соответствующих материалов и, следовательно, изучение атомного строения и электронных особенностей таких ЛЦУ структур является актуальной задачей.

В настоящее время объем публикаций по изучению одномерных цепочечных углеродных материалов невелик, что во многом обусловлено несовершенством известных методов синтеза [1-3]. Первые микрокристаллы карбина размером около $100 \mathrm{~nm}$ были получены термическим отжигом [4]. Они представляли собой протонированные углеродные цепи, имеющие стабилизирующие примеси на их концах. В дальнейшем было предложено много различных методов синтеза карбиноподобных структур, но в результате получались аморфные или плохо упорядоченные пленки и порошки с размером кристаллитов менее $100 \mathrm{~nm}$. Наилучшие результаты получены при синтезе с использованием вакуумных технологий $[5,6]$. В этом случае удалось получить пленки с гексагонально-упакованной цепочечной структурой (ЛЦУ) толщиной в сотни нанометров и межцепочечным расстоянием $5 \AA$.

Исследованные в настоящей работе образцы пленок ЛЦУ выращивались на подложках из поликристаллической меди и монокристаллического кремния путем ионно-стимулированной конденсации из углеродной плазмы в узком диапазоне найденных экспериментально оптимальных параметров синтеза $[5,6]$. Экспериментальная установка для осаждения пленок ЛЦУ представляла собой вакуумную систему, которая обеспечивала импульсный пучок ионов из углеродной плазмы в сочетании с облучением ионами аргона. Толщина полученных пленок составляла 20 и $400 \mathrm{~nm}$. Методом рентгеновской фотоэлектронной спектроскопии (РФЭС) наряду с $s p^{2}$ и $s p^{3}$-связями в образцах было обнаружено наличие углеродной связи с $s p^{1}$-гибридизацией [7], поэтому пленки были классифицированы как карбинсодержащие. Методом комбинационного рассеяния [8] получена карта пространственного распределения цепочечных структур в образцах с микронным разрешением.

В качестве экспериментальных методов в настоящей работе использованы методы фотоэлектронной эмиссии (OSEE) (рис. 1,a) и контактной разности потенциалов (КРП, метод Кельвина, рис. 1,b). Выполнены измерения работы выхода и других параметров энергетической структуры цепочечных углеродных покрытий в вакууме и воздушной среде.

Установка для зондовых измерений КРП на воздухе APS02 фирмы KP Technology показана на рис. $1, b$. 


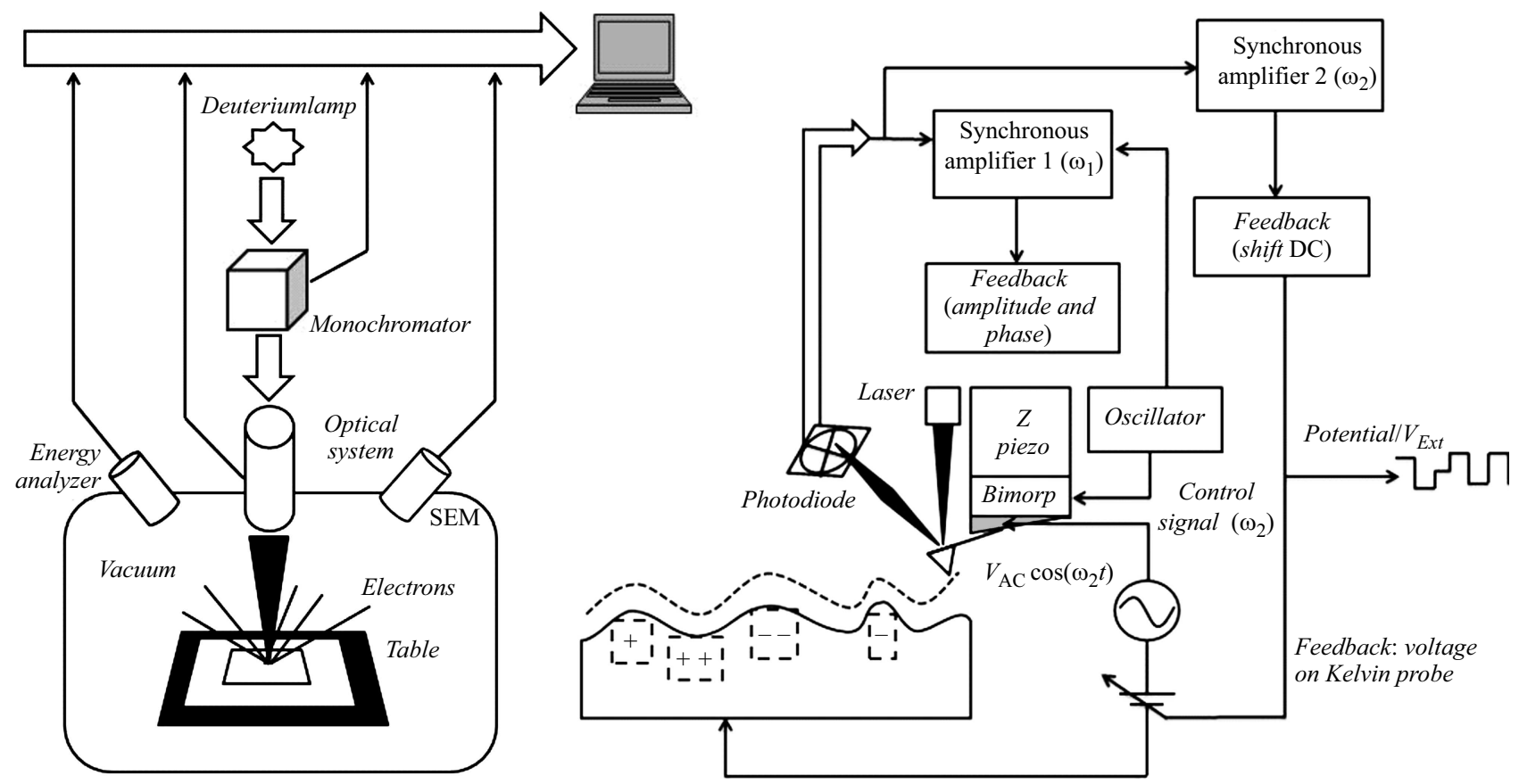

Рис. 1. Схема: $a-$ спектрометра OSEE, $b-$ метода зонда Кельвина.

Таблица 1. Энергетические характеристики поверхности углеродных пленок по данным AVS

\begin{tabular}{l|c|c|c|c}
\hline \multicolumn{1}{c|}{ Образцы ЛЦУ } & Контактная разность потенциалов, $\mathrm{meV}$ & Уровень Ферми, $\mathrm{eV}$ & $\mathrm{PE}, \mathrm{eV}$ & Работа выхода, $\mathrm{eV}$ \\
\hline на меди $(400 \mathrm{~nm})$ & 131 & 4.82 & 4.88 & 4.821 \\
на меди $(20 \mathrm{~nm})$ & 156 & 4.84 & 5.07 & 4.846 \\
на кремнии $(400 \mathrm{~nm})$ & 140 & 4.83 & 5.00 & 4.830 \\
на кремнии $(20 \mathrm{~nm})$ & 133 & 4.82 & 5.09 & 4.823
\end{tabular}

Во время измерений спектров фотоэмиссии (APS) $[9,10]$ образцы с пленками ЛЦУ устанавливались на круглой алюминиевой пластине с возможностью перемещения в трех направлениях. Зонд, имеющий наконечник из золотого сплава диаметром $2 \mathrm{~mm}$, располагался вертикально над образцом.

Зонд калибровали по эталону из золотой фольги, контактная разность потенциалов (КРП) зонда была на $114 \mathrm{mV}$ ниже, чем у эталона. Метод APS использовался для определения энергетического положения валентной зоны образцов. С этой целью производилось сканирование в УФ диапазоне от 180 до $340 \mathrm{~nm}$ $(6.9-3.6 \mathrm{eV})$ аналогично работе [11]. Для обеспечения контакта с верхней поверхностью образцов применялся медный зажим. Измерения проводились в одной точке в центральной области образцов. Определения работы выхода/положения валентной зоны выполнены с использованием линейной экстраполяции экспериментальных данных.

Опытный образец спектрометра оптический стимулированной электронной эмиссии использован для измерений спектральной зависимости электронной эмиссии при варьировании температуры в интервале $20-400^{\circ} \mathrm{C}$ (рис. $1, a)$. Излучение от дейтериевой лампы фокусировалось оптической системой в световой зонд и вызывало эмиссию низкоэнергетических электронов с поверхности образца. Поток электронов регистрировался в режиме счета вторичным электронным умножителем (SEM). Спектры фотоэлектронной эмиссии, полученные в наших экспериментах, были нормированы относительно светового потока источника. Спектральная ошибка спектрометра составляла менее $0.03 \mathrm{eV}$, в то время как ошибка регистрации интенсивности не превышала $5 \%$.

Дополнительная погрешность, вызванная нестационарностью OSEE, была ниже интенсивности фона и на 2-3 порядка ниже величины полезного сигнала. Полученные неселективные спектральные зависимости были обработаны с использованием оригинального программного обеспечения „OSEE-fitter“ [12].

Результаты измерений APS на воздухе для тонких углеродных покрытий на различных подложках показаны на рис. 2. Слабая зависимость интенсивности эмиссии от типа подложки наблюдается только для толстых пленок $(400 \mathrm{~nm})$, кривые для тонких пленок фактически совпадают. 

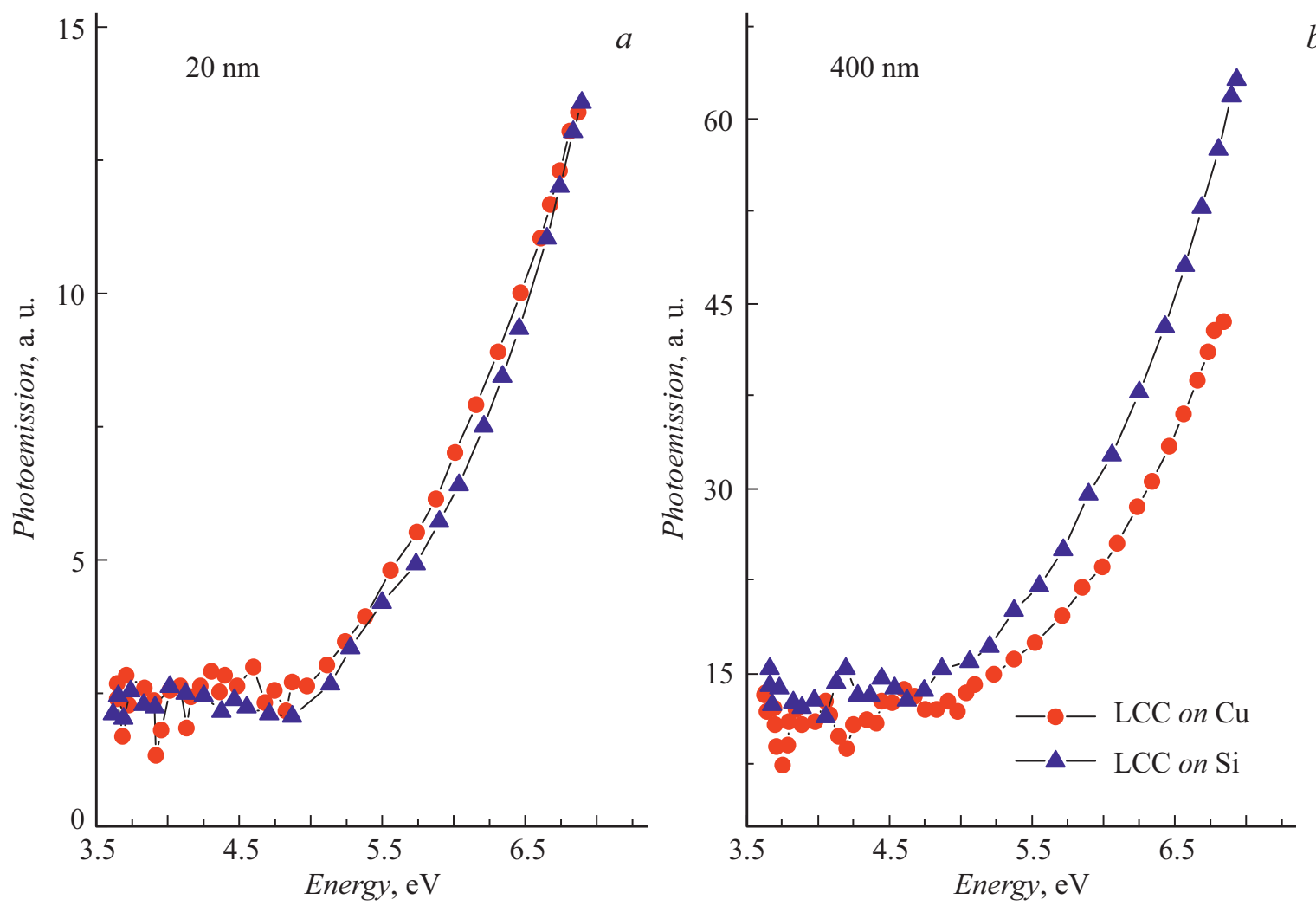

Рис. 2. Результаты APS, полученные для пленок ЛЦУ толщиной 20 (a) и $400 \mathrm{~nm}(b)$ на медной и кремниевой подложках.

По результатам многократных измерений была определена средняя контактная разность потенциалов, рассчитаны положения уровня Ферми и работа выхода. Данные, полученные методом APS для всех образцов, приведены в табл. 1. Установлено, что положение уровня Ферми практически неизменно $(4.83 \pm 0.01 \mathrm{eV})$ для всех исследованных образцов. Положение валентной зоны образцов пленок на $\mathrm{Cu}$ - и $\mathrm{Si}$-подложках меньше при толщине пленки $400 \mathrm{~nm}$ по сравнению с тонкой пленкой $(20 \mathrm{~nm})$. Разница в положении валентной зоны составляла $0.19 \mathrm{eV}$ для пленок на $\mathrm{Cu}$ и $0.9 \mathrm{eV}$ для пленок на $\mathrm{Si}$.

Результаты исследований вакуумной OSEE для тонкого углеродного покрытия при комнатной и повышенной $\left(100^{\circ} \mathrm{C}\right)$ температурах показаны на рис. 3. Как и в случае APS, существенное различие кривых наблюдается для толстых пленок, что может быть связано с зависимостью работы выхода ЛЦУ от температуры.

Для обработки эмиссионных спектров использован степенной закон Кейна [13], хорошо описывающий высокоэнергетическое возбуждение OSEE:

$$
I=A(h v-\Phi)^{n},
$$

где $A$ - параметр аппроксимации, $\Phi$ - работа выхода электрона, $n-$ степенной коэффициент, который связан с доминирующим типом электронных переходов.

Эмиссию в диапазоне $5.5-6.2 \mathrm{eV}$ (рис. 3) можно связать с оптическими переходами между состояниями
Таблица 2. Значения работы выхода углеродных пленок по результатам измерений OSEE

\begin{tabular}{c|c|c}
\hline Температура, ${ }^{\circ} \mathrm{C}$ & ЛЦУ $20 \mathrm{~nm} \Phi, \mathrm{eV}$ & ЛЦУ $400 \mathrm{~nm} \Phi, \mathrm{eV}$ \\
\hline 20 & 3.67 & 4.46 \\
100 & 3.85 & 4.52
\end{tabular}

ЛЦУ и последующим тепловым выходом электронов в вакуум.

Параметры аппроксимирующих кривых OSEE приведены в табл. 2. При обработке экспериментальных данных были получены значения степенных коэффициентов $n=2.1-3.0$, что указывает на участие в процессе эмиссии как прямых, так и непрямых оптических переходов.

Тонкие пленки ЛЦУ демонстрируют достаточно стабильное значение вблизи $n=2.7$ во всем интервале температур. Это означает, что электронная эмиссия в основном обусловлена непрямыми переходами между поверхностными энергетическими зонами с участием фононных процессов [13]. Из табл. 2 видно, что значение $\Phi$ варьирует от 4.0 до $4.5 \mathrm{eV}$ для образцов пленок толщиной $400 \mathrm{~nm}$, при этом величина работы выхода меньше на $0.1-0.2 \mathrm{eV}$ для пленок толщиной $20 \mathrm{~nm}$.

Известно $[5,6]$, что структура тонкой пленки в пределах $20 \mathrm{~nm}$ более совершенна и в меньшей степени зависит от типа подложки, чем в случае толстых по- 

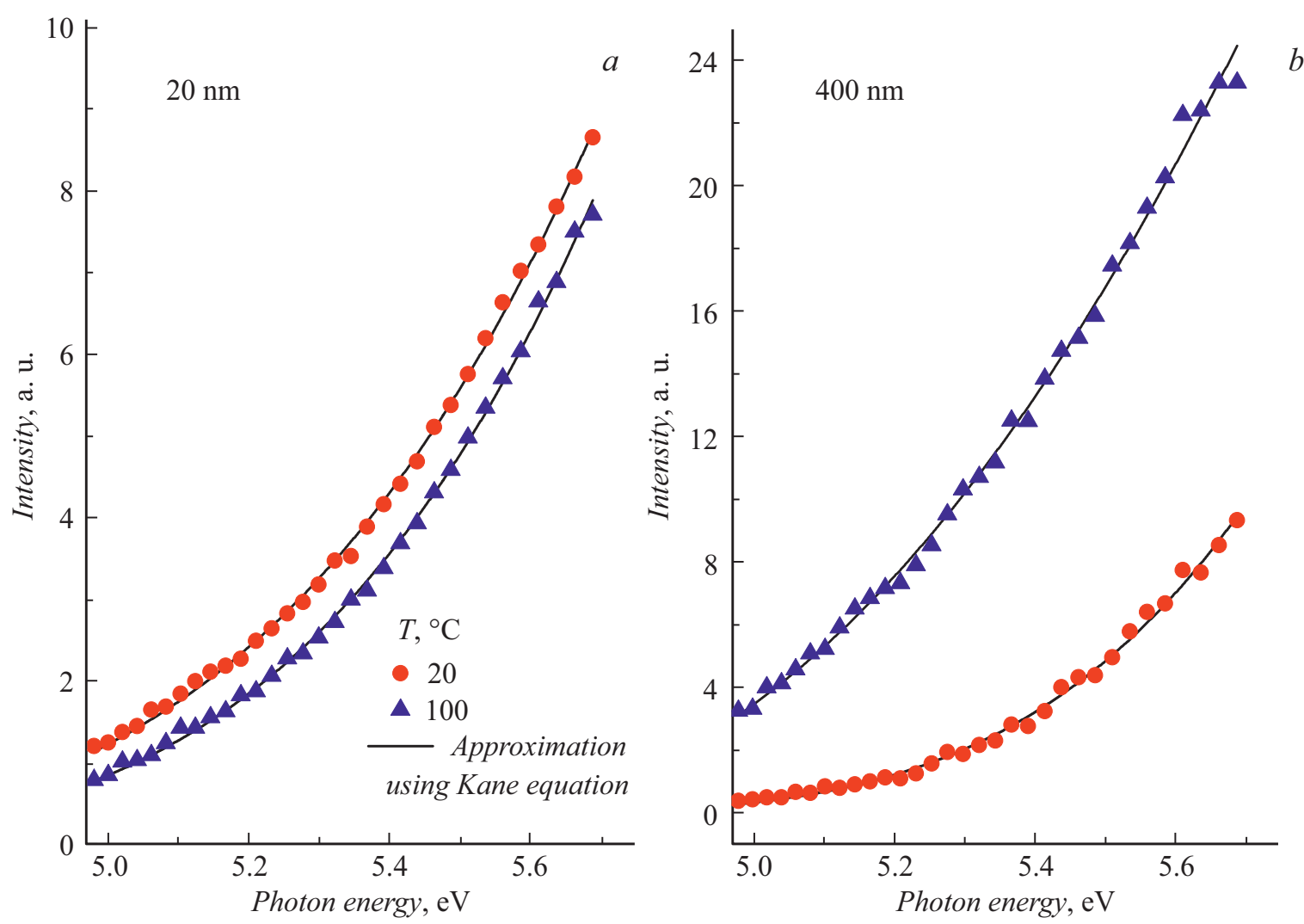

Рис. 3. Аппроксимация высокоэнергетической части спектров OSEE для карбиносодержащих пленок толщиной $20(a)$ и $400 \mathrm{~nm}(b)$ на медной подложке с использованием уравнения Кейна.

крытий ЛЦУ. Данный факт подтверждается результатами OSEE- и APS-измерений. Для пленок толщиной $400 \mathrm{~nm}$ интенсивность эмиссии электронов демонстрирует более выраженную зависимость от типа подложки и температуры. В то же время величина работы выхода в обоих случаях слабо зависит от внешних факторов и обусловлена распределением заряда вблизи концов цепочек.

Известно, что преимуществом одномерных углеродных цепей (карбина) является низкая работа выхода (порядка $0.4 \mathrm{eV}$ ) [13], что противоречит полученным в настоящей работе значениям, достигающим $4.8 \mathrm{eV}$. Существуют, по крайней мере, две возможных причины столь значительного различия. Во-первых, исследуемые карбинсодержащие пленки представляют собой композит из фазовых включений с $s p^{3}-, s p^{2}$ - и $s p^{1}$-связями [9]. Иначе говоря, в OSEE- и APS-измерениях регистрируется усредненное значение работы выхода. С другой стороны, согласно данным [14], аномально низкое значение потенциального барьера на поверхности реализуется только при малом межэлектродном расстоянии в сильном поперечном электрическом поле.

Таким образом, в настоящей работе методами вакуумной фотоэлектронной эмиссии и атмосферной фотоэмиссионной спектроскопии установлено, что работа выхода электрона слабо зависит от толщины углеродных пленок на подложках, что указывает на близость работ выхода подложки и углеродного покрытия. Для тонких пленок $(20 \mathrm{~nm})$ значительный вклад в эмиссию обусловлен приповерхностными атомами подложки. В то же время интенсивность эмиссии электронов в случае толстых пленок $(400 \mathrm{~nm})$ слабо зависит от типа подложки и резко возрастает с повышением температуры эксперимента.

Совокупность полученных спектральных и температурных зависимостей свидетельствует об информативности методов OSEE и APS для оценки качества углеродных покрытий на подложках.

\section{Финансирование работы}

Работа выполнена в рамках государственного задания Минобрнауки РФ № 3.1485.2017/4.6 при поддержке постановления № 211 Правительства Российской Федерации, контракт № 02.А03.21.0006.

\section{Благодарности}

Авторы благодарны проф. В.Д. Кочакову за помощь в подготовке пленок ЛЦУ, а также Iain Baikie за помощь в измерении фотоэлектронной эмиссии при атмосферном давлении. 


\section{Конфликт интересов}

Авторы заявляют, что у них нет конфликта интересов.

\section{Список литературы}

[1] Mingjie L. // ACS Nano 2013. Vol. 7. P. 10075-100082. https://doi.org/10.1021/nn404177r

[2] Christopher B., Goldman N. // J. Phys. Chem. C. 2015. Vol. 119. P. 21605-21611. https://10.1021/acs.jpcc.5b03781

[3] Bitao P. // Sci. Adv. 2015. Vol. 1. e1500857. https://doi.org/10.1126/sciadv.1500857

[4] Сладков А.М., Касаточкин В.И., Коршак В.В., Кудрявцев Ю.П. Диплом на открытие № 107. Б.И. 1972. № 6.

[5] Kudryavtsev Yu.P., Guseva M.B., Babaev V.G. // Carbon. 1992. Vol. 30. P. 213-221.

[6] Luth $H$. Solid Surfaces, Interfaces and Thin Films. Heidelberg: Springer, 2010. $586 \mathrm{p}$.

[7] Зацепин А.Ф., Бунтов Е.А., Защепин Д.А., Бокизода Д.А., Гусева М.Б., Вяткина С.П., Касьянова А.В. // Ядерная физика и инжиниринг. 2018. Т. 9. № 1. С. 94-98.

[8] Buntov E.A., Zatsepin A.F., Slesarev A.I., Shchapova Yu.V., Challinger S., Baikie I. // Carbon. 2019. Vol. 152. P. 388395.

[9] Harwell J.R., Baikie T.K., Baikie I.D., Payne J.L., Ni C., Irvine J.T.S., Turnbull G.A., Samuel I.D.W. // Phys. Chem. Chem. Phys. 2016. Vol. 18. N 29. P. 19738-19745.

[10] Rietwyk K.J., Keller D.A., Majhi K., Ginsburg A., Priel M., Barad H.-N., Anderson A.Y., Zaban A. // Adv. Mater. Interfaces. 2017. Vol. 4. N 16. P. 1700136.

[11] Baikie I.D., Grain A.C., Sutherland J., Law J. // Appl. Surf. Sci. 2014. Vol. 323. P. 45-53.

[12] Бунтов Е.А., Защепин А.Ф. Реестр программ для электронно-вычислительных машин. № 2008614289. 2008.

[13] Kane E.O. // Phys. Rev. 1962. Vol. 127. P. 131-141.

[14] Праздников Ю.Е., Божско А.Д., Гусева М.Б., Новиков Н.Д. // Вестн. Моск. ун-та. Сер. 3. Физ. астрон. 2004. № 5. C. 37-41. 